\title{
PENGARUH PROGRAM FULL DAY SCHOOL TERADAP PRESTASI BELAJAR SISWA PADA MATA PELAJARAN FIQIH DI MADRASAH IBTIDAIYAH (MI) DARUSSALAM LUBUKLINGGAU
}

\section{By: Joni Helandri and Menik}

Dosen PAI STAI Bumi Silampari

jonihelandri@staibsllg.ac.id

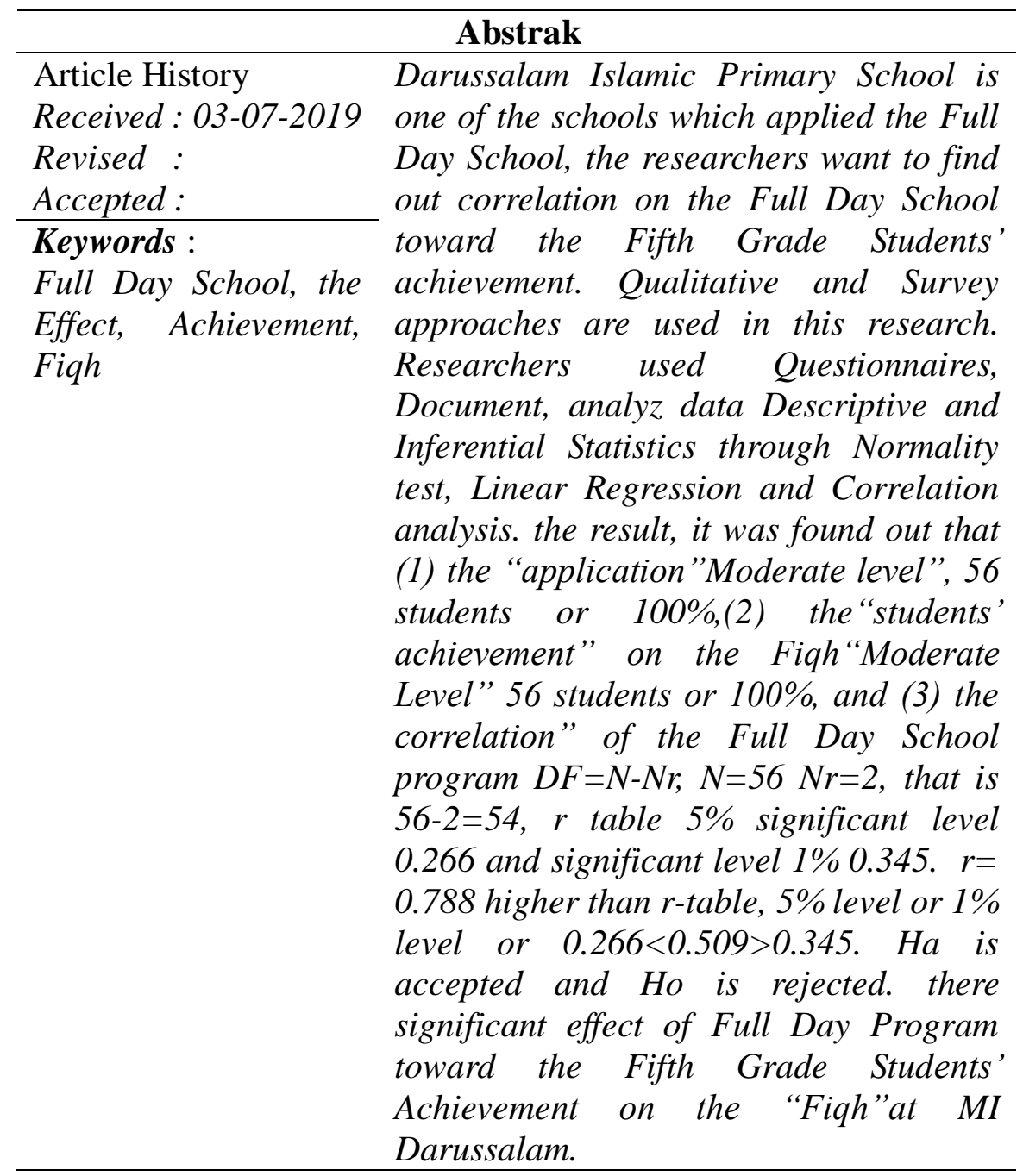




\section{Pendahuluan}

Pendidikan merupakan proses pengubahan sikap dan tata laku seseorang atau kelompok orang, guna mendewasakan manusia melalui upaya pengajaran dan pelatihan. Dalam pengertian luas, pendidikan juga dapat diartikan sebagai sebuah proses dengan metode-metode tertentu sehingga orang memperoleh pengetahuan, pemahaman, nilai-budaya, sebagai panduan bertingkah laku dan bermasyarakat (Syah, 2017:10). Islam sebagai sebuah agama telah memberikan tuntunan yang jelas dalam upaya pendidikan dan pembinaan anak, yang tertuang dalam kitab suci Al-Qur'an, agar seorang anak menjadi generasi yang rabbani. Dengan memberikan pendidikan yang baik dan benar sejak dini, maka anak akan tumbuh menjadi insan yang mencin tai Allah dan Rosul-Nya, berbakti pada orang tua dan memiliki kepribadian yang luhur.

Anak sebagai generasi penerus haruslah mendapat perhatian dan pendidikan yang serius. Baik atau buruk perkembangan dan pendidikan anak bermula dari sini, apabila sejak dini anak dididik dengan baik, maka kelak besarnya juga akan memiliki pendidikan yang baik, begitu juga sebaliknya. Sebagaimana di jelaskan dalam sebuah hadits yang berbunyi:

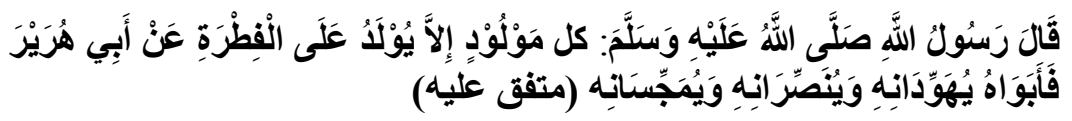

Terjemahannya: "Setiap bayi lahirkan atas dasar fitrah, maka kedua orang tuanyala yang menjadikannya Yahudi, Nasrani, atau Majusi" (HR Muslim)

Peran orang tua untuk membimbing pertumbuhan anaknya sejak dini menjadi sangat urgen bagi peletakan dasar pendidikan atau kehidupan anaknya dikemudian hari. Namun pada kenyataanya, tidak sedikit keluarga yang tidak cukup mampu memberikan pendidikan agama yang baik pada anak. Hal ini mungkin disebabkan karena kurangnya pengetahuan agama orang tua, kesibukan orang tua, dan kurangnya perhatian orang tua terhadap pendidikan agama anak. Realita semacam ini tentu akan berimbas pada pengajaran pendidikan agama Islam dan pembentukan perilaku keagamaan pada anak. Selain orang tua, lembaga pendidikan formal memegang peran yang tidak 
kalah penting bagi peletakan dasar pendidikan agama pada anak disamping pendidikan umum.

Dari uraian di atas, menunjukkan bahwa pendidikan merupakan sarana yang penting untuk meningkatkan kualitas manusia pada setiap aspek kehidupannya. Melihat begitu pentingnya pendidikan, maka perlu adanya perhatian yang serius berkenaan dengan konsep pendidikan agar dapat mencapai tujuan pendidikan secara maksimal. Tujuan pendidikan nasional Indonesia adalah untuk mengembangkan potensi peserta didik agar menjadi manusia yang beriman dan bertaqwa pada tuhan Yang Maha Esa, berakhlak mulia, sehat, berilmu, cakap, kreatif, mandiri, dan menjadi warga negara yang demokratis serta bertanggung jawab (Sikdiknas,2011: 6) Pada era reformasi sebagaimana sekarang ini pembaharuan demi pembaharuan selalu diupayakan agar pendidikan benar-benar memberikan kontribusi yang signifikan dalam rangka mencerdaskan kehidupan bangsa berdasarkan Pancasila. Pendidikan menjadi citacita bagi setiap umat manusia terutama yang cinta kepada kebaikan karena pendidikan merupakan salah satu media untuk mengangkat derajat manusia, bangsa, dan negara sekaligus menyadarkan mereka untuk menuju kepada kebahagiaan di dunia dan di akhirat. Hal tersebut sebagaimana firman Allah dalam QS. Al Mujadilah: 11.

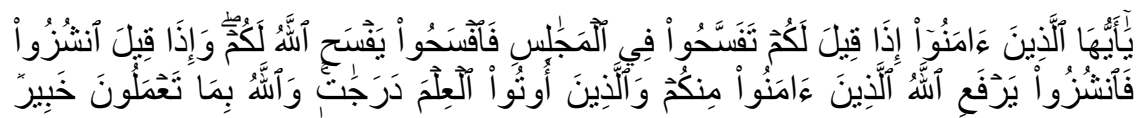

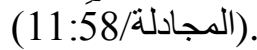

Terjemahannya: "Hai orang-orang beriman apabila dikatakan kepadamu: "Berlapang-lapanglah dalam majlis", maka lapangkanlah niscaya Allah akan memberi kelapangan untukmu. Dan apabila dikatakan: "Berdirilah kamu", maka berdirilah, niscaya Allah akan meninggikan orang-orang yang beriman di antaramu dan orangorang yang diberi ilmu pengetahuan beberapa derajat. Dan Allah Maha Mengetahui apa yang kamu kerjakan.

Pendidikan menjadi salah satu indikator untuk mengukur kemajuan dan derajat kemakmuran suatu negara. Untuk dapat mewujudkan pendidikan nasional yang baik maka perlu adanya perubahan-perubahan dalam segala bidang, termasuk dalam bidang pendidikannya. Kemajuan dunia yang berjalan dengan kecepatan tinggi ini harus direspons secara serius oleh lembaga pendidikan agar 
anak didik siap menghadapi gempuran dunia yang demikian dahsyat. Oleh karena itu, diperlukan terobosan-terobosan untuk meningkatkan kualitas lembaga pendidikan.

Dalam konteks ini, full day school hadir sebagai solusi alternatife yang sangat efektif untuk meningkatkan kualitas pendidikan secara optimal. Full day school adalah sekolah sepanjang hari atau sehari penuh. Biasanya dimulai pada pukul 07:00-16:00. Sekolah model ini masih tergolong langka di Indonesia. Mayoritas lembaga pendidikan masih mengikuti konvensional dalam alokasi waktu belajar, yaitu sekitar setengah mulai jam 07:00-12:00 atau 13:00 siang hari (Asmani, 2017:8). Full day school atau sekolah sehari penuh merupakan salah satu wacana yang dilontarkan oleh Muhadjir Effendy di awal masa jabatannya sebagai Mentri Pendidikan dan Kebudayaan (Mendikbud). Wacana yang dicetuskan pada tanggal 7 Agustus 2016 ini langsung menuai pro dann kontra dari berbagai kalangan masyarakat. Berbagai tanggapan positif dan negatif pun bermunculan dengan alasan masing-masing. Tanggapan positif didasarkan bahwa sistem ini dinilai dapat dapat digunakan untuk meningkatkan kualitas pendidikan. Sebab, sistem ini memberikan banyak waktu bagi siswa untuk memanfaatkan waktu di luar jam sekolah biasnya dengan kegiatan yang mendukung belajar. Semantara itu, tanggapan negatif pun mempunyai alasan kuat. Salah satu alasannya dalah kekhawatiran bahwa sistem full day school justru akan membebani para siswa. Masyarakat juga termakan anggapan bawa pendidikan full day school akan memeberatkan anak. Yang kita lihat sekarang adalah, mayoritas karakteristik pelajar sekarang adalah memanfaatkan waktu luang untuk hal-hal yang tidak bermanfaat, misalnya bermain menonton televisi, bermain play station, pergaulan bebas, dan sejenisnya, bukan digunakan untuk investasi masa depan, seperti bekerja, belajar, berorganisasi, dan kegiatan positif lainnya.

Di sinilah nilai strategisnya eksistensi sekolah model full day school. ia mampu menumbuhkan semangat, kegigihan, dan konsistensi dalam belajar. Anak menjadi produktif memanfaatkan waktu untuk hal-hal yang positif-konstruktif, biasa dengan kultur kompetisi ketat, dan tidak pernah menyerah menghadapi tantangan dan rintangan silih berganti. Dari sini, kreatifitas anak akan berkembang. Madrasah Ibtidaiyah Darussalam Lubuklinggau merupakan salah satu sekolah yang telah menerapkan sistem full day 
school. Sekolah yang didesain sedemikian rupa dengan harapan menghasilkan output yang berkualitas bukan hanya dari sisi pendidikan umumnya saja, tetapi juga pendidikan agamanya. Atas dasar beberapa pernyataan di atas, penulis tertarik untuk meneliti penerapan sistem full day school di lembaga pendidikan tersebut. Dalam penelitian ini, peneliti mengangkat judul "Pengaruh Program Full Day School Terhadap Prestasi Belajar Siswa Pada Mata Pelajaran Fiqih di Madrasah Ibtidaiyah (MI) Darussalam Lubuklinggau".

\section{Metode Penelitian}

\section{Jenis dan Pendekatan Penelitian}

Penelitian ini menggunakan pendekatan kuantitatif yang menggunakan analisis data statistic. Sifat penelitian adalah korelasi (correlational resercah), Variabel yang dilibatkan adalah variabel pengaruh (full day school) dan variabel terpengaruh (prestasi belajar siswa pada mata pelajaran Fiqih).

\section{Subjek Penelitian}

Subjek penelitian adalah seluruh siswa kelas V yang berjumlah 56 siswa. Sehubungan dengan itu, Suharsimi menyatakan bahwa "apabila subjeknya kurang dari 100 lebih baik diambil semuanya sehingga peneliti merupakan penelitian populasi, selanjutnya jika subjeknya lebih besar dapat diambil 10-15\% atau 15-20\% atau lebih".

Tabel 1. Subjek Penelitian Siswa MI Darussalam Lubuklinggau Tahun Pelajaran 2017/2018

\begin{tabular}{lcccc} 
No & Kelas & Laki-laki & Permpuan & Jumlah \\
1 & V.A & 14 & 12 & 26 \\
2 & V.S & 17 & 13 & 30 \\
\multicolumn{2}{l}{ Jumlah total } & 31 & 25 & 56
\end{tabular}

Sumber Data: Dokumentasi MI Darussalam Lubuklinggau TP. 2018/2019

Metode Pengumpulan Data 
Dalam rangka mendapatkan data-data yang dibutuhkan penulis mengguanakan metode-metode sebagai berikut: Angket

Kuesioner yang dimaksudkan sebagai suatu daftar pertanyaan untuk memperoleh jawaban dari responden (orang-orang yang menjawab).

\section{Dokumentasi}

Penulis menggunakann dokumentasi untuk mendapatkan data tentang prestasi siswa dalam pelajaran Fiqih melalui nilai raport, disamping itu untuk mendapatkan data tentang letak geografis, jumlah guru dan karyawan, keadaan siswa dan keadaan sarana prasarana dan lain-lain.

\section{Kisi-kisi Instrumen dan Tekhnik Pengujian Validitasi dan} Perhitungan Reliabelitas Instrumen

\section{Full Day School}

1) Kisi-kisi Instrumen Full Day School

Butir- butir instrumen pengukuran variabel full day school yang disusun berdasarkan kisi-kisi sebagai berikut:

Tabel 2. Kisi-kisi Instrumenn Pengukuran Full Day School

\begin{tabular}{|c|c|c|c|}
\hline & \multirow{2}{*}{ Komponen } & \multirow{2}{*}{ Indikator } & $\begin{array}{c}\text { Butir } \\
\text { Pernyataan }\end{array}$ \\
\hline & & & $\begin{array}{c}\text { No Butir } \\
\text { Pernyataan }\end{array}$ \\
\hline 1 . & $\begin{array}{l}\text { Membentuk sikap } \\
\text { yang Islami }\end{array}$ & $\begin{array}{l}\text { Pengetahuan dasar } \\
\text { tentang Iman, Islam, } \\
\text { Ihsan } \\
\text { Akhlak terpuji dan } \\
\text { tercela }\end{array}$ & $1,2,3,4,5$ \\
\hline 2. & $\begin{array}{l}\text { Pembiasaan } \\
\text { berbudaya Islam }\end{array}$ & Adab-adab Islam & $5,6,7,8,9,10$ \\
\hline
\end{tabular}




$\begin{array}{|llc|}\text { 3. } \begin{array}{l}\text { Penguasaan } \\ \text { pengetahuan } \\ \text { keterampilan }\end{array} & \text { dan } \begin{array}{l}\text { Pengetahuan mater- } \\ \text { materi dan terampil } \\ \text { beribadah sehari-hari }\end{array} & 11,12,13,14, \\ & \text { Jumlah } & 15 \\ & & 15\end{array}$

Teknik Pengujian Validitasi dan Perhitungan Reliabelitas Instrumen Full Day School

Instrumen variabel full day school terdiri dari 15 pernyataan pengolahan data uji validitas instrumen ini dilakukan dengan menggunakan microsoft excel dengan menggunakan rumus statistik "Product Moment" (Sudijono,2012:190) Validitas butir instrumen ditentukan dengan membandingakan antara $r_{\text {hitung }}$ dengan $r_{\text {tabel }}$. Jika $r_{\text {hitung }}>r_{\text {tabel }}$ maka butir tersebut dinyatakan valid dan selanjutnya dapat digunakan untuk pengumpulan data. Sebaiknya jika $r_{\text {hitung }}<r_{\text {tabel }}$ maka butir tersebut dinyatakan tidak valid. Validitas yang tinggi pula, syarat adalah kalau r kritis 0,3. (Sudjono,2012:188)

\section{Prestasi Belajar Siswa}

Kisi-kisi Instrumen Prestasi Belajar

Tabel 3. Kisi-kisi Instrumen Prestasi Belajar Siswa

\begin{tabular}{|l|l|l|c|}
\hline \multirow{2}{*}{ No } & Ranah & Indikator & $\begin{array}{c}\text { Butir } \\
\text { Pernyataan }\end{array}$ \\
\cline { 3 - 4 } & & & $\begin{array}{c}\text { No Butir } \\
\text { Pernyataan }\end{array}$ \\
\hline $1 . \quad$ Kognitif & Menunjukkan & \\
& & Membandingkan \\
& & \\
& & \\
& & \\
& & \\
& & \\
& & \\
& & \\
& &
\end{tabular}




\begin{tabular}{|c|c|c|c|}
\hline & & Menyimpulkan & \\
\hline \multirow[t]{4}{*}{2.} & Afektif & $\begin{array}{l}\text { Sikap menerima } \\
\text { Berpartisipasi }\end{array}$ & \multirow{4}{*}{$6,7,8,9,10$} \\
\hline & & $\begin{array}{l}\text { Menganggap penting } \\
\text { dan bermanfaat }\end{array}$ & \\
\hline & & Mengakui dan meyakini & \\
\hline & & $\begin{array}{l}\text { Menjelmakan } \\
\text { pribadi dan } \\
\text { sehari-hari }\end{array}$ & \\
\hline \multirow[t]{3}{*}{3.} & Psikomotorik & $\begin{array}{l}\text { Mengkoordinasi gerak } \\
\text { mata, tangan, kaki dan } \\
\text { anggota tubuh lainnya }\end{array}$ & \multirow{3}{*}{$\begin{array}{c}11,12,13,14 \\
15\end{array}$} \\
\hline & & Mengucapkan & \\
\hline & & $\begin{array}{l}\text { Membuat mimik dan } \\
\text { gerakan jasmani }\end{array}$ & \\
\hline
\end{tabular}

Teknik Pengujian Validitasi dan Perhitungan Reliabelitas Instrumen Prestasi Belajar

Instrumen variabel prestasi belajar terdiri dari 15 pertanyaan pengolahan data uji validitas instrumen ini dilakukan dengan menggunakan microsoft excel dengan menggunakan rumus statistik "Product Moment", Validitas butir instrumen ditentukan dengan membandingakan antara $r_{\text {hitung }}$ dengan $r_{\text {tabel. }}$. Jika $r_{\text {hitung }}>r_{\text {tabel }}$ maka butir tersebut dinyatakan valid dan selanjutnya dapat digunakan untuk pengumpulan data. Sebaiknya jika $r_{\text {hitung }}<r_{\text {tabel }}$ maka butir tersebut dinyatakan tidak valid. Dalam hal ini analisis item ini Marsun menyatakan. 


\section{Pembahasan}

\section{Penerapan Program Full Day School}

Setelah melakukan uji coba instrumen penelitian yang berjumlah 15 item pertanyaan, dan disebarkan kepada 25 responden, kemudian dilakukan pengujian validitas dan reliabelitas istrumen dengan menggunakan microsoft excel dan Sofware SPSS 22 dengan menggunakan rumus statistik "Product Moment". Validitas butir instrumen ditentukan dengan membandingakan antara $r_{\text {hitung }}$ dengan $r_{\text {tabel. }}$. Jika $r_{\text {hitung }}>r_{\text {tabel }}$, dan syarat minimum $\left(r_{\text {kritis }}\right)$ sehingga item soal dapat dinyatakan valid adalah 0.3 , sehingga jika rhitung $>0.3$, maka butir tersebut dinyatakan valid dan selanjutnya dapat digunakan untuk pengumpulan data. Karena hasil uji validitas menyatakan 30 item pertanyaan diyatakan valid, maka semua item dapat digunakan untuk pengumpulan data. Untuk mengetahui bagaimana penerapan program Full Day School, penulis telah mengajukan 15 item pertanyaaan kepada 56 orang siswa sebagai sampel penelitian dalam bentuk angket tertutup dengan 5 alternatif jawaban, yaitu a, b, c, d, dan e. Skor yang diperoleh dari responden dikelompokan menjadi tabel untuk mencari harga Mean (M) dan Standar Deviasi (SD), maka diperoleh data sebagai berikut:

Tabel 4. Skor Penerapan Program Full Day School

\begin{tabular}{|l|l|l|l|l|l|l|}
\hline 57 & 57 & 57 & 56 & 55 & 57 & 58 \\
\hline 65 & 64 & 55 & 57 & 56 & 60 & 57 \\
\hline 54 & 60 & 58 & 58 & 53 & 58 & 51 \\
\hline 68 & 56 & 60 & 54 & 54 & 61 & 57 \\
\hline 59 & 64 & 49 & 57 & 59 & 55 & 54 \\
\hline 59 & 60 & 55 & 55 & 57 & 58 & 56 \\
\hline 61 & 56 & 60 & 53 & 60 & 51 & 59 \\
\hline 60 & 56 & 57 & 55 & 63 & 56 & 57 \\
\hline
\end{tabular}

Tabel 5. Distribusi Frekuensi Program Full Day School Di MI Darussalam Lubuklinggau

\begin{tabular}{|c|c|c|c|c|c|c|c|c|}
\hline $\begin{array}{c}\text { Interval } \\
(\mathbf{X})\end{array}$ & $\mathbf{F}$ & $\mathbf{X}$ & $\mathbf{F}_{\mathbf{X}}$ & $\mathbf{X}$ & $\begin{array}{c}\mathbf{( X - \dot { X } )} \\
|\mathbf{X}|\end{array}$ & $\mathbf{F X}$ & $\mathbf{X}^{\mathbf{2}}$ & $\mathbf{F X}^{\mathbf{2}}$ \\
\hline $\mathbf{4 9 - 5 1}$ & 3 & 50 & 150 & -7.13 & 7.13 & 21.375 & 50.77 & 152.2969 \\
\hline $\mathbf{5 2 - 5 4}$ & 8 & 53 & 424 & -4.13 & 4.13 & 33 & 17.02 & 136.125 \\
\hline
\end{tabular}


10 Joni Helandri dan Menik, Pengaruh Program Full Day.....

\begin{tabular}{|c|c|c|c|c|c|c|c|c|}
$\mathbf{5 5 - 5 7}$ & 22 & 56 & 1232 & -1.13 & 1.13 & 24.75 & 1.27 & 27.84375 \\
\hline $\mathbf{5 8 - 6 0}$ & 16 & 59 & 944 & 1.88 & 1.88 & 30 & 3.52 & 56.25 \\
\hline $\mathbf{6 1 - 6 3}$ & 3 & 62 & 186 & 4.88 & 4.88 & 14.625 & 23.77 & 71.29688 \\
\hline $\mathbf{6 4 - 6 6}$ & 3 & 65 & 195 & 7.88 & 7.88 & 23.625 & 62.02 & 186.0469 \\
\hline $\mathbf{6 7 - 6 9}$ & 1 & 68 & 68 & 10.88 & 10.88 & 10.875 & 118.27 & 118.2656 \\
\hline$\sum$ & 56 & 413 & 3199 & 13.13 & 37.88 & 158.25 & 276.61 & 15490.13 \\
\hline
\end{tabular}

Tabel di atas menunjukan bahwa frekuensi tiap kelompok responden dapat dilihat bahwa kelompok 55-57 menempati frekuensi tertinggi. Selanjutnya dicari mean atau rata-rata dengan mengguknakan rumus sebagai berikut:

$\mathrm{M}_{\mathrm{x}}: \frac{\sum f x}{N}=\frac{3199}{56}=57,125$

Setelah itu mencari nilai standar deviasi dengan rumus sebagai berikut:

$$
\begin{aligned}
\mathrm{SD}_{\mathrm{x}} & =\sqrt{\left[\frac{\sum f x^{2}}{N}\right]} \\
& =\sqrt{\left[\frac{[15490.13}{56}\right]} \\
& =\sqrt{276.609464}=16.63
\end{aligned}
$$

Setelah diperoleh nilai mean danstandar deviasi, selanjutnya menempatkan katagori tinggi, sedang, rendah, adpun katagori tersebut adalah sebagai berikut:

Tinggi

$\mathrm{M}+1 . \mathrm{SD}_{\mathrm{X}}=57.13+1 \times 16.63=73.76=74$ ke atas

Sedang

$\mathrm{M}-1 . \mathrm{SD}_{\mathrm{X}}=57.13-1 \times 16.63=42.10=40$

ke bawah

Rendah 
Dari hasil perhitungan di atas, maka skor data tentang Program Full Day School di MI Darussalam Lubuklinggau yang diperoleh melalui penyebaran angket dapat dikelompok sebagai berikut:

1. Skor 74 keatas termasuk katagori tinggi yaitu sebanyak 0 Orang Siswa

2. Skor 40-73 termasuk katagori sedang yaitu sebanyak 56 Orang Siswa

3. Skor 39 ke bawah termasuk katagori rendah yaitu se sebanyak 0 Orang Siswa

Untuk lebih jelasnya dapat ;dilihat tabel berikut ini:

Tabel 6. Kelompok Skor Program Full Day School Di MI Darussalam Lubuklinggau

Kelompok

Tinggi

Sedang

Rendah

\section{F}

0

56

0

$\mathrm{N}=56$
$\%$

0

100

0

100

Dari tabel di atas dapat disimpulkan bahwa kelompok sedang menempati presentase paling tinggi yaitu $100 \%$ atau sekitar 56 orang siswa, kelompok tinggi menempati presentase $0 \%$ atau sekitar 0 orang siswa, sedangkan kelompok rendah yaitu $0 \%$ atau sekitar 0 orang siswa. Dengan demikian dapat dilihat bahwa Program Full Day School di MI Darussalam Lubuklinggau termasuk katagori sedang.

\section{Prestasi Bealajar Siswa Pada Pelajaran Fiqih}

Setelah melakukan uji coba instrumen penelitian yang berjumlah 15 item pertanyaan, dan disebarkan kepada 25 responden, kemudian dilakukan pengujian validitas dan reliabelitas istrumen dengan menggunakan microsoft excel dan Sofware SPSS 22 dengan menggunakan rumus statistik "Product Moment". Validitas butir instrumen ditentukan dengan membandingakan antara $r_{\text {hitung }}$ dengan $r_{\text {tabel. }}$. Jika $r_{\text {hitung }}>r_{\text {tabel }}$, dan syarat minimum ( $r_{\text {kritis }}$ ) sehingga item soal dapat dinyatakan valid adalah 0.3 , sehingga jika rhitung $>0.3$, maka 
butir tersebut dinyatakan valid dan selanjutnya dapat digunakan untuk pengumpulan data. Karena hasil uji validitas menyatakan 30 item pertanyaan diyatakan valid, maka semua item dapat digunakan untuk pengumpulan data. Untuk mengetahui bagaimana prestasi belajar siswa, penulis telah mengajukan 15 item pertanyaaan kepada 56 orang siswa sebagai sampel penelitian dalam bentuk angket tertutup dengan 5 alternatif jawaban, yaitu a, b, c, d, dan e. Skor yang diperoleh dari responden dikelompokan menjadi tabel untuk mencari harga Mean (M) dan Standar Deviasi (SD), maka diperoleh data sebagai berikut:

Tabel 7. Skor Prestasi Belajar siswa pada Mata Pelajaran Fiqih

\begin{tabular}{|l|l|l|l|l|l|l|l|}
\hline 49 & 54 & 62 & 48 & 59 & 59 & 60 & 53 \\
\hline 53 & 54 & 58 & 59 & 56 & 56 & 53 & 54 \\
\hline 56 & 52 & 56 & 59 & 58 & 58 & 53 & 54 \\
\hline 66 & 57 & 60 & 55 & 55 & 55 & 52 & 59 \\
\hline 53 & 56 & 51 & 57 & 55 & 55 & 54 & 58 \\
\hline 63 & 60 & 54 & 55 & 62 & 62 & 58 & 57 \\
\hline 59 & 63 & 54 & 60 & 55 & 55 & 57 & 52 \\
\hline 64 & 53 & 55 & 57 & 58 & 58 & 53 & 58 \\
\hline
\end{tabular}

Tabel 8. Distribusi Frekuensi Prestasi Belajar Siswa Pada Mata

Pelajaran Fiqih Di MI Darussalam Lubuklinggau

\begin{tabular}{|c|c|c|c|c|c|c|c|c|}
\hline $\begin{array}{c}\text { Interval } \\
(\mathbf{X})\end{array}$ & $\mathbf{F}$ & $\mathbf{X}$ & $\mathbf{F}_{\mathbf{X}}$ & $\mathbf{X}$ & $\begin{array}{c}(\mathbf{X}-\dot{\mathbf{X}}) \\
|\mathbf{X}|\end{array}$ & $\mathbf{F}|\mathbf{X}|$ & $\mathbf{X}^{\mathbf{2}}$ & $\mathbf{F X}^{\mathbf{2}}$ \\
\hline $48-50$ & 2 & 65 & 130 & -21.91 & 21.91 & 43.8214 & 480.08 & 960.1588 \\
\hline $51-53$ & 11 & 74 & 814 & -12.91 & 12.91 & 142.018 & 166.69 & 1833.552 \\
\hline $54-56$ & 17 & 83 & 1411 & -3.91 & 3.91 & 66.4821 & 15.29 & 259.9927 \\
\hline $57-59$ & 16 & 92 & 1472 & 5.09 & 5.09 & 81.4286 & 25.90 & 414.4133 \\
\hline $60-62$ & 6 & 101 & 606 & 14.09 & 14.09 & 84.5357 & 198.51 & 1191.048 \\
\hline $63-65$ & 3 & 105 & 315 & 18.09 & 18.09 & 54.2679 & 327.22 & 981.6668 \\
\hline $66-68$ & 1 & 119 & 119 & 32.09 & 32.09 & 32.0893 & 1029.72 & 1029.722 \\
\hline & 56 & 639 & 4867 & 30.63 & 108.09 & 504.643 & 2243.41 & 125631.1 \\
\hline
\end{tabular}

Tabel di atas menunjukan bahwa frekuensi tiap kelompok responden dapat dilihat bahwa kelompok 54-56 menempati frekuensi 
tertinggi. Selanjutnya dicari mean atau rata-rata dengan menggunakan rumus sebagai berikut:

$\mathrm{M}_{\mathrm{x}}: \frac{\sum f x}{N}=\frac{4867}{56}=86.91$

Setelah itu mencari nilai standar deviasi dengan rumus sebagai berikut:

$$
\begin{aligned}
\mathrm{SD}_{\mathrm{x}} & =\sqrt{\left[\frac{\sum f x^{2}}{N}\right]} \\
& =\sqrt{\left[\frac{125631.1}{56}\right]} \\
& =\sqrt{2243.4129}=47.36
\end{aligned}
$$

Setelah diperoleh nilai mean danstandar deviasi, selanjutnya menempatkan katagori tinggi, sedang, rendah, adapun katagori tersebut adalah sebagai berikut:

Tinggi

$\mathrm{M}+1 . \mathrm{SD}_{\mathrm{X}}=86.91+1 \times 47.36=134.28=134$ ke atas

Sedang

$\mathrm{M}-1 . \mathrm{SD}_{\mathrm{X}}=86.91-1 \times 47.36=39.55=40$

ke bawah

Rendah

Dari hasil perhitungan di atas, maka skor data tentang Prestasi Belajar Siswa di MI Darussalam Lubuklinggau yang diperoleh melalui penyebaran angket dapat dikelompok sebagai berikut:

1. Skor 134 keatas termasuk katagori tinggi yaitu sebanyak 0 Orang Siswa

2. Skor 40-133 termasuk katagori sedang yaitu sebanyak 56 Orang Siswa

3. Skor 39 ke bawah termasuk katagori rendah yaitu se sebanyak 0 Orang Siswa

Untuk lebih jelasnya dapat ;dilihat tabel berikut ini: 
Tabel 9. Kelompok Skor Prestasi Belajar Siswa Pada Mata Pelajaran Fiqih Di MI Darussalam Lubuklinggau

$\begin{array}{ccc}\text { Kelompok } & \text { F } & \% \\ \text { Tinggi } & 0 & 0 \\ \text { Sedang } & 56 & 100 \\ \text { Rendah } & 0 & 0 \\ & \mathrm{~N}=56 & 100\end{array}$

Dari tabel di atas dapat disimpulkan bahwa kelompok sedang menempati presentase paling tinggi yaitu $100 \%$ atau sekitar 56 orang siswa, kelompok tinggi menempati presentase $0 \%$ atau sekitar 0 orang siswa, sedangkan kelompok rendah yaitu $0 \%$ atau sekitar 0 orang siswa. Dengan demikian dapat dilihat bahwa Prestasi Belajar Siswa Pada Mata Pelajaran Fiqih di MI Darussalam Lubuklinggau termasuk katagori sedang.

\section{Pengaruh Program Full Day School Terhadap Prestasi Belajar Siswa pada Mata Pelajaran Fiqih}

Sebelum dilakukan pengujian hipotesis penelitian dengan statistika infrensial dilakukan terlebih dahulu uji persyaratan analisis yaitu uji nomalitas data. Uji normalitas dilakukan dengan menggunakan uji Liliefors untuk mengetahui distribusi data, Pengujian dilakukan dengan taraf nyata 0,05 dengan kriteria "data berdistribusi normal apabila $\mathrm{L}$-hitung sama atau lebih besar dari Ltabel". pengujian normalitas dilakuan terhadap nilai galat taksiran variabel endogen atas veriabel eksogen.adapun hasil dari uji normalitas, bahwa L-hitung > L-tabel $/ 0.022>0.001$, maka dinyatakan bahwa data berdistribusi normal sehingga dapat dilakukan uji regresi linear sederhana. Setelah dilakukan uji normalitas, dan data data dinyatakan berdistribusi normal. Selanjutnya dilakukan analisis regresi dan korelasi untuk menguji antar variabel. Regresi adalah bentuk hubungan fungsional antara variabel-variabel. Karena pada penelitian ini hanya melihat hubungan antara dua variabel, yaitu satu variabel terikat (prestasi belajar siswa) dan satu variabel bebas (Full Day School), maka 
analisis regresinya disebut regresi linear sederhana. Adapun hasil uji regresi linier menghasilkan output, nilai $R$ square $=0.509$ dari tabel output analisis regresi linear sederhana di SPSS 22, menunjukan bahwa $25.9 \%$ dari varians prestasi belajar siswa dapat dijelaskan oleh perubahan dalam variabel Full Day School, sedangkan $74.1 \%$ sisanya dijelaskan oleh faktor lain di luar model.

Untuk melakukan uji t atau untuk mengetahui apakah variabel independen (Full Day School) secara parsial berpengaruh signifikan terhadap variabel dependen (prestasi belajar siswa), maka dapat di tentukan dengan rumus sebagai berikut:

$\mathrm{H}_{\mathrm{O}}=\mathrm{a}+\mathrm{BX}$

$\mathrm{H}_{1}=\mathrm{Y} \neq \mathrm{A}+\mathrm{BX}$

Prestasi Belajar $=26.157+0.527 \times$ Full Day School + eror

Berdasarkan nilai signifikan pada variabel Full Day School $=0.000<0.05$ sehingga $\mathrm{H}_{\mathrm{O}}$ ditolak, yang berarti variabel Full Day School secara parsial berpengaruh positif dan signifikan terhadap variabel prestasi belajar siswa, semakin tinggi variabel Full Day School, semakin tinggi variabel prestasi belajar siswa demikian juga sebaliknya. selanjutnya menguji hipotesis yang diajaukan untuk membuktikan hipotesis tersebut, maka dilakukan analisa data dengan menggunakan analisis korelasi. Untuk mengetahui pengaruh atara program Full Day School terhadap prestasi belajar siswa dapat dilihat dari tes yang merupakan variabel X program Full Day School dengan hasil jawaban angket sebanyak 15 item pertanyaan dan untuk variabel Y adalah prestasi belajar siswa dengan melihat hasil jawaban angket sebanyak 15 item pertanyaan. Maka selanjutnya diadakan perhitungan Product Moment dapat dilihat pada tabel sebagai berikut:

Tabel 10. Perhitungan untuk Memperoleh Angka Korelasi antara Variabel X (Program Full Day School) dan Variabel Y (Prestasi Belajar) di MI Darussalam Lubuklinggau

\begin{tabular}{|c|c|c|c|c|c|c|}
\hline NO & $\begin{array}{c}\text { Kode } \\
\text { sampel }\end{array}$ & $\mathbf{X}$ & $\mathbf{Y}$ & $\mathbf{X Y}$ & $\mathbf{X}^{\mathbf{2}}$ & $\mathbf{Y}^{\mathbf{2}}$ \\
\hline 1 & 001 & 53 & 49 & 2597 & 2809 & 2401 \\
\hline 2 & 002 & 65 & 53 & 3445 & 4225 & 2809 \\
\hline 3 & 003 & 54 & 56 & 3024 & 2916 & 3136 \\
\hline
\end{tabular}


16 Joni Helandri dan Menik, Pengaruh Program Full Day.....

\begin{tabular}{|c|c|c|c|c|c|c|}
\hline 4 & 004 & 68 & 66 & 4488 & 4624 & 4356 \\
\hline 5 & 005 & 59 & 53 & 3127 & 3481 & 2809 \\
\hline 6 & 006 & 59 & 63 & 3717 & 3481 & 3969 \\
\hline 7 & 007 & 58 & 59 & 3422 & 3364 & 3481 \\
\hline 8 & 008 & 57 & 64 & 3648 & 3249 & 4096 \\
\hline 9 & 009 & 51 & 54 & 2754 & 2601 & 2916 \\
\hline 10 & 010 & 57 & 54 & 3078 & 3249 & 2916 \\
\hline 11 & 011 & 53 & 52 & 2756 & 2809 & 2704 \\
\hline 12 & 012 & 64 & 57 & 3648 & 4096 & 3249 \\
\hline 13 & 013 & 60 & 56 & 3360 & 3600 & 3136 \\
\hline 14 & 014 & 56 & 60 & 3360 & 3136 & 3600 \\
\hline 15 & 015 & 64 & 63 & 4032 & 4096 & 3969 \\
\hline 16 & 016 & 60 & 53 & 3180 & 3600 & 2809 \\
\hline 17 & 017 & 61 & 62 & 3782 & 3721 & 3844 \\
\hline 18 & 018 & 60 & 58 & 3480 & 3600 & 3364 \\
\hline 19 & 019 & 60 & 56 & 3360 & 3600 & 3136 \\
\hline 20 & 020 & 63 & 60 & 3780 & 3969 & 3600 \\
\hline 21 & 021 & 57 & 51 & 2907 & 3249 & 2601 \\
\hline 22 & 022 & 55 & 54 & 2970 & 3025 & 2916 \\
\hline 23 & 023 & 58 & 54 & 3132 & 3364 & 2916 \\
\hline 24 & 024 & 60 & 55 & 3300 & 3600 & 3025 \\
\hline 25 & 025 & 49 & 48 & 2352 & 2401 & 2304 \\
\hline 26 & 026 & 55 & 59 & 3245 & 3025 & 3481 \\
\hline 27 & 027 & 56 & 59 & 3304 & 3136 & 3481 \\
\hline 28 & 028 & 51 & 55 & 2805 & 2601 & 3025 \\
\hline 29 & 029 & 56 & 57 & 3192 & 3136 & 3249 \\
\hline 30 & 030 & 56 & 55 & 3080 & 3136 & 3025 \\
\hline 31 & 031 & 56 & 60 & 3360 & 3136 & 3600 \\
\hline 32 & 032 & 57 & 57 & 3249 & 3249 & 3249 \\
\hline 33 & 033 & 58 & 59 & 3422 & 3364 & 3481 \\
\hline 34 & 034 & 54 & 56 & 3024 & 2916 & 3136 \\
\hline 35 & 035 & 57 & 58 & 3306 & 3249 & 3364 \\
\hline 36 & 036 & 55 & 55 & 3025 & 3025 & 3025 \\
\hline
\end{tabular}




\begin{tabular}{|c|c|c|c|c|c|c|}
\cline { 2 - 5 } 37 & 037 & 60 & 55 & 3300 & 3600 & 3025 \\
\hline 38 & 038 & 59 & 62 & 3658 & 3481 & 3844 \\
\hline 39 & 039 & 57 & 55 & 3135 & 3249 & 3025 \\
\hline 40 & 040 & 57 & 58 & 3306 & 3249 & 3364 \\
\hline 41 & 041 & 55 & 60 & 3300 & 3025 & 3600 \\
\hline 42 & 042 & 56 & 53 & 2968 & 3136 & 2809 \\
\hline 43 & 043 & 53 & 53 & 2809 & 2809 & 2809 \\
\hline 44 & 044 & 54 & 52 & 2808 & 2916 & 2704 \\
\hline 45 & 045 & 59 & 54 & 3186 & 3481 & 2916 \\
\hline 46 & 046 & 57 & 58 & 3306 & 3249 & 3364 \\
\hline 47 & 047 & 53 & 57 & 3021 & 2809 & 3249 \\
\hline 48 & 048 & 55 & 53 & 2915 & 3025 & 2809 \\
\hline 49 & 049 & 54 & 53 & 2862 & 2916 & 2809 \\
\hline 50 & 050 & 56 & 54 & 3024 & 3136 & 2916 \\
\hline 51 & 051 & 57 & 54 & 3078 & 3249 & 2916 \\
\hline 52 & 052 & 60 & 59 & 3540 & 3600 & 3481 \\
\hline 53 & 053 & 58 & 58 & 3364 & 3364 & 3364 \\
\hline 54 & 054 & 61 & 57 & 3477 & 3721 & 3249 \\
\hline 55 & 055 & 55 & 52 & 2860 & 3025 & 2704 \\
\hline 56 & 056 & 58 & 58 & 3364 & 3364 & 3364 \\
\hline JUMLAH & & 3206 & 3155 & 180992 & 184242 & 178499 \\
\hline
\end{tabular}

$$
\begin{aligned}
\mathrm{R}_{X Y} & =\frac{N \sum X Y-\left(\sum X\right)\left(\sum Y\right)}{\sqrt{\left\{\left(N \sum X^{2}\right)-\left(\sum X\right)^{2}\right\}\left\{\left(N \sum Y^{2}\right)-\left(\sum Y\right)^{2}\right\}}} \\
& =\frac{56 \times 180992-(3206) \times(3155)}{\sqrt{\left\{(56 \times 184242)-(3206)^{2}\right\}\left\{(56 \times 178499)-(3155)^{2}\right\}}} \\
& =\frac{10135552-101114930}{\sqrt{\{(10317552)-(10278436)\}\{(9995944)-(9954025)\}}} \\
& =\frac{20622}{\sqrt{39116 \times 41919}} \\
& =\frac{20622}{\sqrt{1639703604}} \\
& =\frac{20622}{40493.25381}=0.509270016=0.509
\end{aligned}
$$


Berdasarkan hasil perhitungan di atas, diperoleh " $r_{\mathrm{xy}}$ " sebesar 0.509 selanjutnya membandingkan " $\mathrm{r}_{\mathrm{xy}}$ " dengan " $\mathrm{r}_{\text {tabel }}$ Product Moment, dengan terlebih dahulu mencari df-nya, rumus $\mathrm{df}$ yaitu $\mathrm{df}=$ $\mathrm{N}$ - nr. Sampel dalam penelitian ini adalah 56 orang, sedangkan variabelnya terdiri dari 2 variabel yaitu variabel $\mathrm{X}$ dan variabel $\mathrm{Y}$, maka $\mathrm{nr}=2$. Setelah diperoleh $\mathrm{N}=56 \mathrm{dan} \mathrm{nr}=2$, maka dfnya adalah 56-2 =54, pada tabel nilai koefisien " $\mathrm{r}$ " Product Moment $\mathrm{df}$ sebesar 54 diperoleh harga " $r_{\text {tabel}}$ " signifikansi $5 \%=0.266$ dan pada taraf signifikansi $1 \%=0.345$. Dengan harga " $r$ " yang diperoleh yaitu 0.788 lebih besar dari nilai " $r_{\text {tabel }}$ ", baik pada taraf $5 \%$ maupun pada taraf $1 \%$ atau $0.266<0.509>0.345$. Ini berati $\mathrm{H}_{\mathrm{a}}$ (Hipotesis Alternatif) menyatakan ada pengaruh yang signifikan atara program Full Day Schooll terhadap prestasi belajar siswa pada pelajaran fikih di kelas V MI Darussalam Lubuklinggau.

\section{Simpulan}

Pelaksanaan Program Full Day School di MI Darussalam Lubuklinggau, kategori tinggi yaitu 0 orang (0\%), kategori sedang yaitu 56 orang $(100 \%)$, sedangkan kelompok rendah yaitu 0 orang (0\%), disimpulkan penerapan Program Full Day School di MI Darussalam Lubuklinggau termasuk katagori sedang.

Prestasi belajar siswa pada mata pelajaran fiqih di MI Darussalam Lubuklinggau, kategori tinggi yaitu 0 orang $(0 \%)$, kategori sedang yaitu 56 orang (100\%), sedangkan kelompok rendah yaitu 0 orang $(0 \%)$, disimpulkan prestasi belajar siswa pada mata pelajaran fiqih di MI Darussalam Lubuklinggau termasuk katagori sedang.

Pengaruh program Full Day School terhadap prestasi belajar siswa pada mata pelajaran fiqih di MI Darussalam Lubulinggau, diperoleh " $\mathrm{r}_{\mathrm{xy}}$ " sebesar 0.509 selanjutnya membandingkan " $\mathrm{x}_{\mathrm{xy}}$ " dengan " $\mathrm{r}_{\text {tabel }}$ Product Moment, df yaitu $\mathrm{df}=\mathrm{N}-\mathrm{nr}$. $\mathrm{N}=56$ dan $\mathrm{nr}=$ 2. $\mathrm{Df}=56-2=54$, pada tabel nilai koefisien " $\mathrm{r}$ " Product Moment $\mathrm{df}$ sebesar 54 diperoleh harga " $r_{\text {tabel }}$ " signifikansi $5 \%=0.266$ dan pada taraf signifikansi $1 \%=0.345$. Dengan harga " $r$ " yang diperoleh yaitu 0.788 lebih besar dari nilai " $r_{\text {tabel }}$ ", baik pada taraf 5\% maupun pada taraf $1 \%$ atau $0.266<0.509>0.345 . \mathrm{H}_{\mathrm{a}}=$ ada pengaruh yang signifikan atara program Full Day Schooll terhadap prestasi belajar siswa pada pelajaran fikih di kelas V MI Darussalam Lubuklinggau. 


\section{DAFTAR PUSTAKA}

Ahmadi, A. 1991. Psikologi Belajar. Jakarta: Rieneka Cipta.

Ahyadi, A., A. 1991. Psikologi Agama, Bandung: Sinar Baru.

Arikunto, S. 2006. Prosedur Penelitian: Suatu Pendekatan Praktis. Jakarta: PT. Rineka Cipta.

Asmani, J., M. 2017. Full Day School Konsep Manajemen \& Quality Control. Yogyakarta: Ar-Ruzz Media.

Asmani, J., M. 2001. Tuntunan Lengkap Metodologi Praktis Penelitian Pendidikan. Yogyakarta: Cetakan ke-1, Diva Press.

Ayun, Q. 2013 http://qurrrotaayun.blogspot.co.id/2013/06/sistempendidikan-fullday-schooldan.html, diakses [2018, September 20:50:13]

Basuki,S. Harus Proposional sesuai Jenis dan Jenjang Sekolah, http://www.strkN1lmj.sch.id/?duakses[2018, Mei 11:45.25]

Chotimah, C. 2011. Peranan "Full Day School" dalam Pengembangan Pembelajaran Pendidikan Agama Islam, Surabaya: Perpustakan UIN Sunan Ampel.

Departemen Agama. 1994. Al-Qur'an dan Terjemahannya. Jakarta: Lembaga Penterjemah dan Pentashih Kitab Suci Al-Qur'an.

Departemen Agama RI. 2004. Kurikulum 2004, Standar Kompetensi. Jakarta: Dirjen Bimbaga Islam.

Djamarah, S.,B. 1994. Prestasi Belajar dan Kompetensi Guru, Surabaya: Usaha Nasional.

Echlos, M,.J.\& Shadily, H. 2012. Kamus Inggris Indonesia, Jakarta: Gramedia.

Ibusud“Fulldaykordegarden",http//www.ibusd.drca.us/mainofices/res 
rch/pdf/studies/Fulldaykordegarden.pdf, di akses [2018, September 21:16:25]

J. Lexy Moleong, L., L. 2012. Metodologi Penelitian Kualitatif, Jakarta: PT. Remaja Rosdakarya.

Kuntjaraningrat. 1990. Metode Penelitian Masyarakat, Jakarta: Gramedia.

Echols, M., J. \& Shadily, H. 1996. Kamus Inggris-Indonesia. Jakarta: Gramedia Pustaka Utama,

Meliana. 2008. "Pengaruh Kedisiplinan terhadap Prestasi Belajar Pendidikan Agama Islam Siswa Menengah Kejuruan Negeri Lubuklinggau", Skripsi S-1 pada STAIS Bumi Silampari Lubuklinggau, Lubuklinggau : STAIS Bumi Silampari Lubuklinggau.

Muslim. Al Imam. 1997. Terjemahan Hadis Shahih Muslim. Cetakan ke-5, Klang Book Centre, Malasyia.

Nelita. 2007. "Hubungan Metode Belajar dengan Prestasi Siswa dalam Bidang Studi Pendidikan Agama Islam di SM Muhamadiyyah 1 Lubuklinggau", Skripsi $S-1$ pada STAIS Bumi Silampari Lubuklinggau, Lubuklinggau : STAIS Bumi Silampari Lubuklinggau.

Ridwan. 2011. Dasar-dasar Statistika, Alfabeta, Bandung.

Sehudin. 2005. Pengaruh Pelaksanaan Pembelajaran Full Day School Terhadap Akhlak Siswa. Perpustakaan IAIN SONDIN, Surabaya.

Sekolah Tinggi Agama Islam (STAI) Bumi Sillampari, Pedoman Penulisan Karya Ilmiah.

Slameto. 2017. Belajar dan Faktor-Faktor yang Mempengaruhinya, Rineka Cipta, Jakarta. 
Sismanto,http://mkpd.wordpress.com/2007/05/21/menakarkapitalisasi \%E2\%809Cfulldayschool\%E2\%80\%9D/. di akses[2018, September 20:41:36.

Sugiyono. 2008. Statistik Untuk Penelitian. Bandung: Alfabeta.

Sudjana, N. 2011. Langkah dan Prosedur Penelitian, Bekasi: Publishing.

Sudujono, A. 2001. Pengantar Statistik Pendidikan, Jakarta: Raja Grafindo Persada.

Supardi, D., S. 2009. Pengantar Statistik Pendidikan, Jakarta: Diadit Media.

Suryabrata, S. 2006. Psikologi Pendidikan. Jakarta: Rajawali Press.

Syafi'i, K. 2001. Fiqih Ushul Fiqih AIN, STAIN, PTAIS Fakultas Tarbiyah Komponen MKDK, Bandung: Pustaka Setia.

Syah, Muhibbin 2017. Psikologi Pendidikan dengan Pendekatan Baru. Bandung: PT Remaja Rosdakarya.

Undang-undang Republik Indonesia No 20 tahun 2003 tentang Sisdiknas dan Peraturan Pemerintah Tahun 2010 tentang Penyelenggaraan Pendidikan serta Wajib Belajar 2011. Citra Umbara, Bandung. 